\title{
The LUNG SAFE: a biased presentation of the prevalence of ARDS!
}

\author{
Jesús Villar ${ }^{1,2^{*}}$, Marcus J. Schultz $z^{3}$ and Robert M. Kacmarek ${ }^{4,5}$
}

\begin{abstract}
The recent Large Observational Study to Understand the Global Impact of Severe Acute Respiratory Failure (LUNG SAFE) challenges current data on the prevalence of acute respiratory distress syndrome (ARDS). The LUNG SAFE investigators claimed that their data demonstrated the predictive validity of the Berlin criteria. Also, the LUNG SAFE showed a disturbingly large gap between scientific evidence and medical practice. All of these statements demand that we question the interpretations of the study's findings.
\end{abstract}

The fundamental feature of a scientific system is not that its propositions are verifiable, but that its propositions are falsifiable.

\section{Karl Popper}

Acute respiratory distress syndrome (ARDS) is an acute and intense inflammatory response of the lungs that occurs as a result of either a direct or an indirect insult to the alveolar capillary membrane, causing increased permeability and subsequent interstitial and alveolar pulmonary edema. Characterized clinically by severe hypoxemia and bilateral radiographic infiltrates, ARDS usually occurs in previously healthy people. Usually, there is a latent period of 18-24 $\mathrm{h}$ between the insult and the development of the full-blown clinical syndrome. After this period, tachypnea, labored breathing, and cyanosis are observed. ARDS is generally confirmed by arterial hypoxemia and generalized infiltrates on chest radiograph, and the abnormalities in lung mechanics and oxygenation are better assessed once the patient is intubated and receiving mechanical ventilation (MV). Since 1967, little change in ventilator practice occurred until the publication of the pivotal ARMA trial [1] demonstrated that a lung-protective strategy using a tidal volume $\left(\mathrm{V}_{\mathrm{T}}\right)$ of $4-8 \mathrm{ml} / \mathrm{kg}$ of predicted body weight

\footnotetext{
* Correspondence: jesus.villar54@gmail.com

${ }^{1}$ CIBER de Enfermedades Respiratorias, Instituto de Salud Carlos III, Madrid, Spain

${ }^{2}$ Multidisciplinary Organ Dysfunction Evaluation Research Network, Research Unit, Hospital Universitario Dr. Negrin, Barranco de la Ballena, s/n-4th floor, South Wing, Las Palmas de Gran Canaria, Spain

Full list of author information is available at the end of the article
}

(PBW) and moderate levels of positive end-expiratory pressure (PEEP) improved survival. Since then, limitation of $\mathrm{V}_{\mathrm{T}}$ to $6-8 \mathrm{ml} / \mathrm{kg} \mathrm{PBW}$ and plateau pressure to a maximum of $30 \mathrm{cmH}_{2} \mathrm{O}$, and application of PEEP between 10 and $16 \mathrm{cmH}_{2} \mathrm{O}$ represents the standard for MV in ARDS patients.

To date, efforts to diagnose or describe ARDS by one or more laboratory tests have failed. When defining ARDS, the specific ranges and conditions under which to evaluate the hypoxemia (most frequently assessed by the partial pressure of oxygen in arterial blood/fraction of inspired oxygen $\left(\mathrm{PaO}_{2} / \mathrm{FiO}_{2}\right)$ ratio) have varied considerably. The original description [2], the American-European Consensus Committee [3], and the Berlin criteria [4] proved to be incapable of identifying uniform groups of patients in terms of severity and outcome [5-8] since none of them consider the sensitivity of $\mathrm{PaO}_{2} / \mathrm{FiO}_{2}$ to ventilator settings and the effects of routine care during the first $24 \mathrm{~h}$ for appropriate stratification, categorization, and prognostication [8]. There are no data that link a particular baseline $\mathrm{PaO}_{2} / \mathrm{FiO}_{2}$ to predictable structural changes in the alveolar capillary membrane. In addition, no biomarker has been described that is specific for ARDS, so it is plausible that ARDS prevalence is overestimated because many patients with acute hypoxemic respiratory failure from other diseases with bilateral pulmonary opacities and infiltrates [9] or patients with atelectasis, cardiogenic pulmonary edema, fluid overload, and obesity could be incorrectly diagnosed as having ARDS. Misdiagnosis can also occur if clinicians consider qualifying $\mathrm{PaO}_{2}$ values resulting from acute events unrelated to the disease process instead of 
considering only $\mathrm{PaO}_{2}$ values while patients are clinically stable [10].

The recent Large Observational Study to Understand the Global Impact of Severe Acute Respiratory Failure (LUNG SAFE) [11] challenges all of these statements and demands that we question the interpretations of its findings. The LUNG SAFE investigators reported an ARDS prevalence of $10.4 \%$ of all ICU admissions and of $23.4 \%$ of all patients receiving $\mathrm{MV}$, a huge figure exceeding by an order of magnitude that expected from current clinical experience in Europe [12-15]. At least four sources of bias could explain this surprisingly epidemic figure.

First, $40 \%$ of ARDS cases were included using an algorithm-recognition ARDS tool while participating clinicians did not diagnose them as ARDS. Considering all of the alternate causes of hypoxemia already listed that present as bilateral infiltrates on chest radiograph, it is quite challenging to disregard the clinician's bedside interpretation that ARDS was not present for that of a computer algorithm which does not take into consideration these issues. How was the algorithm validated?

Second, more than $17 \%$ of patients diagnosed with ARDS based on the Berlin criteria did not fulfill the criteria $24 \mathrm{~h}$ after routine care. Actual ARDS does not resolve in $24 \mathrm{~h}$. Those patients who did not continue to meet criteria after $24 \mathrm{~h}$ most likely did not have ARDS and most likely had an alternate cause of hypoxemia and bilateral infiltrates that could be rapidly reversed [8-10].

Third, the study was performed in a short 4-week period during the winter of 2014, when prevalence of pulmonary infections, including H1N1 infection, had a seasonal peak [16] (pneumonia was reported to be almost 4-fold that of sepsis, a figure not supported by previous incidence studies) [12-15]. It is inappropriate to extrapolate data derived during a known worst seasonal period of a condition to represent the prevalence of the condition year around.

Finally, ICUs that did not enroll at least one ARDS patient during those 4 weeks were excluded from the analysis. This may be the most biasing problem of all. How can it be justified to eliminate data from groups originally designed to be part of the study of prevalence simply because they did not have a patient who met the criteria during the study period? The distribution of ARDS patients differs from institution to institution. Referral centers can be expected to have a higher prevalence than the average ICU, which may have periods without any ARDS patients. All should be considered in determining global prevalence.

Overall until now, the hospital mortality rate of patients with ARDS has remained $>40 \%$ in major observational studies [15]. Based on the $p$ value for the $5 \%$ absolute differences between the reported mortality rate of mild vs moderate ARDS and moderate vs severe
ARDS, the LUNG SAFE investigators claimed that their data demonstrated the predictive validity of the Berlin criteria. What matters, however, is the probability that when you find that a result is "statistically significant" there is actually a real effect [17]. The Berlin definition does not help in segmenting patients into homogeneous subgroups with similar lung injury and outcome at its onset $[8,18]$. Notably, there were no standard rules for measuring the $\mathrm{PaO}_{2} / \mathrm{FiO}_{2}$ at any time during the LUNG SAFE, and it was not reported how many patients within each category remained in the same category after the first 24 h of routine care. From this point of view, hospital mortality differences (calculated by us) between mild and moderate ARDS $(p=0.022)$ and between moderate and severe ARDS $(p=0.03)$ are meaningless since the use of nonstandardized $\mathrm{PaO}_{2} / \mathrm{FiO}_{2}$ measurement makes it difficult, if not impossible, to interpret the degrees of lung injury [18]. Of note, patients categorized as having severe ARDS, based on the Berlin definition, were younger and had fewer comorbidities and a worse outcome, a finding that contradicts previous knowledge [19]. There is still a need for a better ARDS definitio$\mathrm{n}$-one that takes into consideration the patient's actual ventilator settings and the fact that over the first $24 \mathrm{~h}$ of presumed ARDS, as the patient is stabilized, the true severity of the syndrome is identified and the status of many patients dramatically improves during this period.

Also, the LUNG SAFE investigators constructed 28-day survival curves for every ARDS category with missing patients in each category and assumed that patients discharged from the hospital before day 28 were alive. Mortality is a crucial outcome that should be measured very precisely. Causes of mortality were not reported. Patients with mild forms of ARDS do not die from ARDS but from the underlying disease (cancer, acquired immunodeficiency syndromes, stroke, advanced age), usually once discharged from the ICU [10]. Finally, surprisingly, the use of adjunctive therapies was analyzed after reclassifying patients using selectively the worst value of $\mathrm{PaO}_{2} / \mathrm{FiO}_{2}$ over the course of ICU stay instead of using the initial categorization, as the Berlin criteria mandate.

Besides all of these methodological sources of bias, a very relevant contribution of the LUNG SAFE is that it shows a disturbingly large gap between scientific evidence and medical practice. Most patients enrolled in this study were ventilated with $\mathrm{V}_{\mathrm{T}}>7 \mathrm{ml} / \mathrm{kg} \mathrm{PBW}, \mathrm{PEEP}<10 \mathrm{cmH}_{2} \mathrm{O}$, and $\mathrm{FiO}_{2}>0.6$ and did not have their plateau pressure measured. A significant proportion of patients were ventilated with $\mathrm{V}_{\mathrm{T}}>9 \mathrm{ml} / \mathrm{kg}$ and less than $18 \%$ of patients received PEEP $>11 \mathrm{cmH}_{2} \mathrm{O}$. It would be interesting to see whether there was a correlation between applied $\mathrm{V}_{\mathrm{T}}$ and PEEP with worsening lung damage or with mortality. Why were proven therapies such as low- $\mathrm{V}_{\mathrm{T}} \mathrm{MV}$, moderate to high levels of PEEP, and limitation of plateau pressure indeed 
ignored? Thus, it can only be assumed that there is still a huge need to assist the medical community in understanding the importance of lung-protective ventilation in all patients we mechanically ventilate.

\section{Ethics statement}

Not applicable.

\section{Consent statement}

Not applicable.

\section{Abbreviations}

ARDS: acute respiratory distress syndrome; ARMA: A Respiratory Management in Acute Lung Injury/ARDS trial; LUNG SAFE: Large Observational Study to Understand the Global Impact of Severe Acute Respiratory Failure; MV: mechanical ventilation; $\mathrm{PaO}_{2} / \mathrm{FiO}_{2}$ : partial pressure of oxygen in arterial blood/fraction of inspired oxygen; PBW: predicted body weight; PEEP: positive end-expiratory pressure; $\mathrm{V}_{\mathrm{T}}$ : tidal volume.

\section{Competing interests}

$J V$ has received research grants from Maquet. RMK has received research grants from Venner Medical and Covidien, and is a consultant for Covidien and Orange Med Inc. MJS has no competing interests.

\section{Authors' contributions}

JV conceived the manuscript, participated in its design and coordination, and helped to draft the manuscript. MJS conceived the manuscript, participated in its design and coordination, and helped to draft the manuscript. RMK conceived the manuscript, participated in its design and coordination, and helped to draft the manuscript. All authors read and approved the final manuscript

\section{Acknowledgments}

This work was supported in part by Instituto de Salud Carlos III (CB06/06/ 1088, Pl13/0119) and Asociación Científica Pulmón y Ventilación Mecánica. The funders had no role in the content, decision to publish, or preparation of the manuscript.

\section{Author details}

'CIBER de Enfermedades Respiratorias, Instituto de Salud Carlos III, Madrid, Spain. ${ }^{2}$ Multidisciplinary Organ Dysfunction Evaluation Research Network, Research Unit, Hospital Universitario Dr. Negrin, Barranco de la Ballena, s/ n-4th floor, South Wing, Las Palmas de Gran Canaria, Spain. ${ }^{3}$ Department of Intensive Care, Academic Medical Center, Amsterdam, The Netherlands. ${ }^{4}$ Department of Respiratory Care, Massachusetts General Hospital, Boston, MA, USA. ${ }^{5}$ Department of Anesthesiology, Harvard University, Boston, MA, USA.

Published online: 25 April 2016

\section{References}

1. The ARDS Network. Ventilation with lower tidal volumes as compared with traditional tidal volumes for acute lung injury and the acute respiratory distress syndrome. N Engl J Med. 2000;342:1301-8.

2. Ashbaugh DG, Bigelow DB, Petty TL, Levine BE. Acute respiratory distress in adults. Lancet. 1967:2:319-23.

3. Bernard GR, Artigas A, Brigham KL, Carlet J, Falke K, Hudson L, et al. The American-European Consensus Conference on ARDS. Am J Respir Crit Care Med. 1994;149:818-24

4. The ARDS Definition Task Force. Acute respiratory distress syndrome: the Berlin definition. JAMA. 2012:307:2526-33.

5. Villar J, Pérez-Méndez L, Kacmarek RM. Current definitions of acute lung injury and the acute respiratory distress syndrome do not reflect their true severity and outcome. Intensive Care Med. 1999;25:930-5.

6. Hernu R, Wallet F, Thiollière F, Martin O, Richard JC, Schmitt Z, et al. An attempt to validate the modification of the American-European consensus definition of acute lung injury/acute respiratory distress syndrome by the Berlin definition in a university hospital. Intensive Care Med. 2013;39:2161-270.
7. Caser EB, Zandonade E, Pereira E, Gama AM, Barbas CS. Impact of distinct definitions of acute lung injury on its incidence and outcomes in Brazilian ICUs: prospective evaluation of 7,133 patients. Crit Care Med. 2014;42:574-82.

8. Villar J, Pérez-Méndez L, Blanco J, Añón JM, Blanch L, Belda J, et al. A universal definition of ARDS: the $\mathrm{PaO}_{2} / \mathrm{FiO}_{2}$ ratio under a standard ventilatory setting. $A$ prospective, multicenter validation study. Intensive Care Med. 2013;39:583-92.

9. Gibelin A, Parrot A, Maitre B, Brun-Buisson C, Mekontso Dessap A, Fartoukh $\mathrm{M}$, et al. Acute respiratory distress syndrome mimickers lacking common risk factors of the Berlin definition. Intensive Care Med. 2016:42:164-72.

10. Villar J, Fernández RL, Ambrós A, Parra L, Blanco J, Domínguez-Berrot AM, et al. A clinical classification of the acute respiratory distress syndrome for predicting outcome and guiding medical therapy. Crit Care Med. 2015;43: 346-53.

11. Bellani G, Laffey JG, Pham T, Fan E, Brochard L, Esteban A, et al. Epidemiology, patterns of care, and mortality for patients with acute respiratory distress syndrome in intensive care units in 50 countries. JAMA. 2016;315:788-800.

12. Linko R, Okkonen M, Pettilä V, Perttilä J, Parviainen I, Ruokonen E, et al. Acute respiratory failure in intensive care units. FINNALI: a prospective cohort study. Intensive Care Med. 2009;35:1352-61.

13. Villar J, Blanco J, Añón JM, Santos-Bouza A, Blanch L, Ambrós A, et al. The ALIEN study: incidence and outcome of acute respiratory distress syndrome in the era of lung protective ventilation. Intensive Care Med. 2011:37:1932-41.

14. Sigurdsson Ml, Sigvaldason K, Gunnarsson TS, Moller A, Sigurdsson GH. Acute respiratory distress syndrome: nationwide changes in incidence, treatment and mortality over 23 years. Acta Anaesthesiol Scand. 2013;57:37-45.

15. Villar J, Blanco J, Kacmarek RM. Current incidence and outcome of the acute respiratory distress syndrome. Curr Opin Crit Care. 2016;22:1-6.

16. Mäkinen TM, Juvonen R, Jokelainen J, Harju TH, Peitso A, Bloigu A, et al. Cold temperature and low humidity are associated with increased occurrence of respiratory tract infections. Respir Med. 2009;103:456-62.

17. Ioannidis JP. Why most published research findings are false. PLoS Med. 2005;2:e124.

18. Villar J, Blanco J, del Campo R, Andaluz-Ojeda, Díaz-Dominguez FJ, Muriel A, et al. Assessment of $\mathrm{PaO}_{2} / \mathrm{FiO}_{2}$ for stratification of patients with moderate and severe acute respiratory distress syndrome. BMJ Open. 2015:5:e006812.

19. Villar J, Pérez-Méndez L, Basaldúa S, Blanco J, Aguilar G, Toral D, et al. A risk tertiles model for predicting mortality in patients with acute respiratory distress syndrome: age, plateau pressure, and $\mathrm{PaO}_{2} / \mathrm{FiO}_{2}$ at ARDS onset can predict mortality. Respir Care. 2011:56:420-8. 